\title{
AOR
}

Selected Papers of \#AolR2019:

The $20^{\text {th }}$ Annual Conference of the Association of Internet Researchers Brisbane, Australia / 2-5 October 2019

\section{THANKS SVETLANA: PRIVACY, TRUST, HUMOR AND THE RUSSIAN PSYOP ON TUMBLR}

Indira Neill Hoch

Concordia College, Moorhead Minnesota, USA

On March $24^{\text {th }}, 2018$, Tumblr account holders received a mass email informing them that 84 user accounts had been terminated. These 84 accounts were determined as "linked to Internet Research Agency or IRA (a group closely tied to the Russian government) posing as members of the Tumblr community." Those receiving the email from Tumblr were identified as having "followed one of these accounts linked to the IRA, or liked or reblogged one of their posts." What followed was a list of the 84 terminated accounts, and all usernames known to be utilized by these accounts. On Tumblr, someone can change their username near-instantly, and doing so is common practice. It's not at all unusual for one blogger to cycle through five, ten, twenty names, while maintaining their followers. It's the person behind the account who is important, not the username. And, it turns out, the fact that on Tumblr the person is who you follow, is what the IRA exploited.

This study uses a combination of multimodal discourse analysis (Bateman, 2008; Holsanova, 2012; Jewitt, 2009; LeVine \& Scollon, 2004) and qualitative interview materials to make an initial attempt at understanding the response to the Russian Psyop as conducted on Tumblr. It is critical that we, as technologically-oriented, civically concerned communication scholars, understand the technical and social mechanisms that allowed Russian interference on social media platforms to be perpetuated, and not only on the most popular and visible sites, such as Facebook and Twitter, but more niche platforms as well. Tumblr remains comparatively under-researched compared to other platforms, but if the IRA took the time to customize their operations to each specific platform, we, are obligated to take the same care in understanding their digital tactics and how they were tailored.

Interview materials originate prior to the announcement, and were conducted from September to November 2017, as part of a larger project aimed towards understanding the socio-technical interaction between the Tumblr platform and users through a social Suggested Citation (APA): Neill Hoch, I. (2019, October 2-5). Thanks Svetlana: Privacy, trust, humor and the Russian Psyop on Tumblr. Paper presented at AolR 2019: The $20^{\text {th }}$ Annual Conference of the Association of Internet Researchers. Brisbane, Australia: AolR. Retrieved from http://spir.aoir.org. 
construction of technology (SCOT) framework (Bijker, Hughes, \& Pinch, 1989). In these interviews, privacy concerns were discussed at length, as well as Tumblr's perceived incompetence when coding and maintaining a platform. Because participants maintained relatively little faith in the digital architecture of Tumblr, they instead largely managed their privacy by carefully considering who they followed and who followed them. When deciding what bloggers to follow, a sense of personal connection to the people they followed was crucial. This centrality of "knowing" who they followed (while almost never knowing the blogger in a face-to-face context) is key for understanding how the Russian accounts must resemble "real" people, in order to gain followers and thus traction on Tumblr.

The posts and reblog chains under analysis either 1) originated with IRA-linked account, "lagonegirl," and were reblogged after "her" blog was deleted, or 2) were humorous responses to the Psyop revelation. These posts were collected the week following the March $24^{\text {th }}, 2018$ announcement.

Usernames listed as IRA-linked included "addictedtoblackk," "blackness-by-your-side," "blacktolive," "postingwhileblack," "blacklivesmatterusa," and "blackprideworldwide." As can perhaps be gleaned from this list of names, many of these IRA accounts were specifically "posing as members" of the Black, politically engaged, Tumblr community. Lagonegirl was one of these users, posing as a Black woman.

Unlike the ads on Facebook purchased from suspicious origins (Kim et al., 2018) or micro-targeting efforts by Cambridge Analytica, the Russian Psyop on Tumblr took a drastically different format. Rather than targeting specific users through ad-buys (something that may not even be possible on Tumblr, which is often derided for absurdist ads with no relation at all to the user base), the IRA accounts instead posed as people. Lagonegirl wasn't focused exclusively on politics, or the charade of being a Black woman. She originated and reblogged a mix of humor, social justice, and everyday occurrences that any other user running a "personal" blog on Tumblr might.

Trust and a sense of authenticity was crucial for interview participants in order to understand the blogs they were following and the people behind those blogs.

Furthermore, it was participants' lack of trust in Tumblr specifically that led them to rely so intensely on feeling a personal connection (whether real or imaginary) to the person behind the blog. One participant, E, answered the question of whether or not they followed blogs they had no particular connection to as such,

E: $\mathrm{mm}$ not really? $\mathrm{i}$ think every blog i follow $\mathrm{i}$ feel some kind of connection to, even if its just a familiar "oh hey this person finished knitting that laceweight shawl! good for them" when i see them on my dash

theyve all become part of the landscape of my dash

Tumblr users who had followed, liked, and/or reblogged posts from IRA-linked accounts were assured in the March $24^{\text {th }}$ email they weren't "in trouble," and that they didn't "need to take any action if you don't want to." But while Tumblr deleted the blogs in question, they made the decision to not delete reblogs of their posts to other accounts, allowing 
users to continue to "curate your own Tumblr to reflect your own personal views and perspectives." It was left up to the individual Tumblr user to decide if they wished to delete posts originating from these accounts from their own blogs. Thus, posts by lagonegirl and other IRA-linked accounts continued to circulate.

Tumblr users responded to the reveal of the Russian "Psyop" with a mix of disbelief, humor, and accusations. Lagonegirl had posted a mixture of affirmations, humor, and political content to "her" blog, and following the IRA announcement "her" posts were reblogged with additional jokes and addendums, or commentary of a more serious nature, as Tumblr users could now analyze "her" political posts (including a number of posts critical of Presidential Candidate Hillary Clinton) through a new lens.

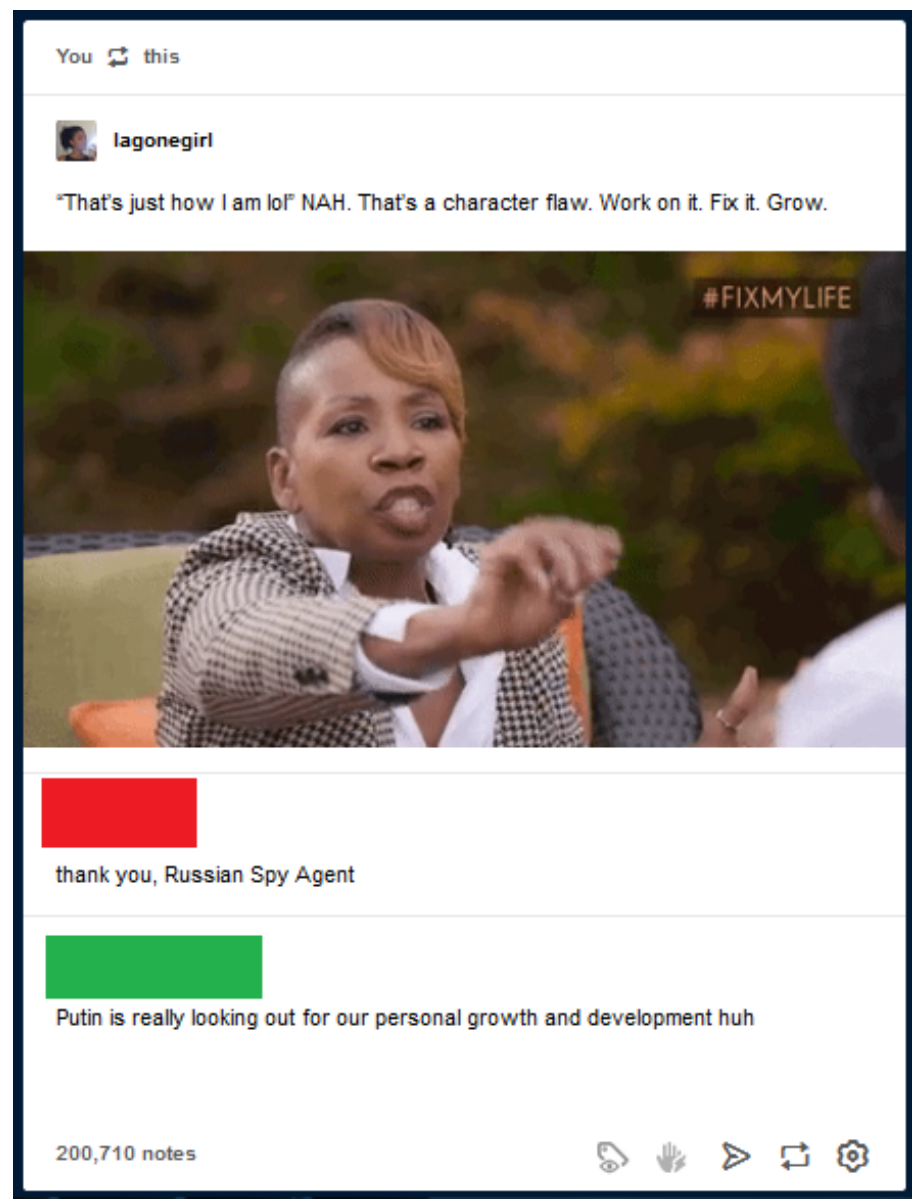

Figure 1. Lagonegirl was an inspiration to us all.

Interview materials offer clarity to how lagonegirl and other IRA-linked blogs became part of the "landscape" of so many Tumblr dashboards seamlessly, while the multimodal analysis of posts offers insights into how deception was maintained and later parodied. The trust that users revoked from Tumblr as a technical platform, and instead placed in their own personal assessment of individual bloggers, emphasizes the sophistication of the Psyop on Tumblr, and how interference programs cannot wholly be remedied by tighter regulation on advertising content on select platforms.

\section{References}


Bateman, J. A., (2008). Multimodality and genre: A foundation for the systematic analysis of multimodal documents. London: Palgrave Macmillan.

Bijker, W.E., Hughes, T.P., \& Pinch, T. (1989). Introduction. In W. E. Bijker, T. P. Hughes, \& T. Pinch (Eds.). The social construction of technological systems: New directions in the sociology and history of technology. (pp. 9-16). Cambridge, MA: MIT Press.

Holsanova, J., 2012. New methods for studying visual communication and multimodal integration. Visual Communication, 11(3), 251-257.

Jewitt, C. (2004). Multimodality and new communication technologies. In P. LeVine, \& R. Scollon, (Eds.) Discourse and technology: Multimodal discourse analysis. (pp. 196-207) Washington D.C: Georgetown University Press.

Kim, Y. M., Hsu, J., Neiman, D., Kou, C., Bankston, L., Kim, S. Y., ... \& Raskutti, G. (2018). The stealth media? Groups and targets behind divisive issue campaigns on Facebook. Political Communication, 35(4), 515-541.

LeVine, P., \& Scollon, R. (Eds.). (2004). Discourse and technology: Multimodal discourse analysis. Washington D.C: Georgetown University Press. 